\title{
Response of Colonic Smooth Muscle from Newborn and Adult Rabbits to Electrical Field Stimulation
}

\author{
RANDI AXELROD, JOHN MARTIN, AND JAMES P. RYAN \\ Departments of Pediatrics and Physiology, Temple University School of Medicine, Philadelphia, Pennsylvania \\ 19140
}

\begin{abstract}
Electrical field stimulation (EFS) of circular smooth muscle from the proximal and distal colon of adult rabbits elicits region-specific patterns of contraction and relaxation referred to as on and off responses. The present study examined EFS-mediated on and of responses in neonatal (3- to 5-d-old), juvenile (2-wk-old), and adult rabbits to determine whether colonic motility undergoes a period of postnatal maturation with respect to the pattern of contraction/relaxation that develops in response to stimulation of the enteric nervous system. Muscle strips from the proximal and distal colon were oriented parallel to the circular muscle layer and stimulated electrically (80 V; 0.5 ms pulse width) for $10 \mathrm{~s}$ using platinum wire electrodes. Stimulus frequency varied between 1 and $64 \mathrm{~Hz}$. EFS stimulation of circular smooth muscle from the proximal colon of neonatal, juvenile, and adult rabbits was characterized by the development of atropine-sensitive on-contractions. The frequency-response curves were similar for each age group. In the distal colon, EFS of circular smooth muscle from neonatal, juvenile, and adult rabbits produced on-relaxations and atropine-insensitive off-contractions. The frequency-response data for the off-contractions were similar for each age group. Although no age-related differences were observed with respect to the pattern of contractile response to EFS, the force of the proximal colon on contractions and the distal colon off-contractions increased as the animals matured. The results suggest that the pattern of colonic enteric neurotransmission is established early in the neonatal period and does not undergo any significant change during the postnatal period. Differences in the force of contraction may reflect differences in the contractility of colonic smooth muscle from neonatal, juvenile, and adult rabbits. (Pediatr Res 35: 470-473, 1994)
\end{abstract}

\section{Abbreviations}

ACh, acetylcholine

EFS, electrical field stimulation

KBS, Kreb's buffer solution

NANC, nonadrenergic, noncholinergic

TTX, tetrodotoxin

VIP, vasoactive intestinal peptide

Gastrointestinal motility in the preterm infant and the newborn infant differs from that of the adult and undergoes a period

Received August 26, 1993; accepted November 29, 1993.

Correspondence and reprint requests: Dr. James P. Ryan, Professor and Acting Chairman, Department of Physiology, Temple University School of Medicine, Philadelphia, PA 19140.

Supported in part by NIH Grant HD21047. of postnatal maturation (1-7). Gastroesophageal reflux, gastroparesis, and abnormal small-bowel contractile patterns are common examples of the altered motility observed in preterm and newborn infants. The factors responsible for the reduced motility in the newborn period remain unsettled. Results from animal models indicate that the increased contractility of esophageal, gastric, and biliary tract smooth muscle that develops during the postnatal period can be accounted for by factors other than increased muscle mass, suggesting fundamental changes in the myogenic and intracellular biochemical processes involved in the excitation-contraction-coupling process (8-13). Studies performed on the human newborn have reported that the postnatal maturation of fasting intestinal motility patterns is paralleled by changes in the fasting levels of gastrointestinal hormones (14, 15). Thus, the data presently available suggest that the postnatal period is characterized by maturation of the myogenic and endocrine factors that influence gut motility.

Using the rabbit as an animal model, we and others have reported that gastric antral smooth muscle contractility undergoes a period of postnatal maturation $(9,11,12)$. We also have reported (16) that differences exist between the newborn and adult rabbit with respect to the response of gastric smooth muscle to EFS. The latter result suggests that neurogenic factors also may be involved in the postnatal development of gastric motility.

It has recently been reported that colonic smooth muscle contractility also may undergo a period of postnatal maturation $(17-22)$. The present study was designed to determine whether the response of colonic smooth muscle to EFS also differs between the newborn and the adult. Previous studies using tissues from adult rabbits have demonstrated that EFS of circular smooth muscle from the proximal and distal colon produces characteristic patterns of contraction/relaxation referred to as on and off responses (23). Snape et al. (23) have shown that EFS of circular muscle from the proximal colon evokes frequency-dependent contractions that occur only during the stimulus (oncontraction), whereas EFS of the distal colon initiates a stimulusinduced on-relaxation, followed by an on-contraction and a poststimulus contraction termed the off-contraction. These EFSinduced responses are mediated via activation of excitatory and inhibitory myenteric neurons located within the wall of the colon (24). The purpose of the present study was to determine whether differences exist between neonates, juvenile, and adult animals with respect to the pattern and/or magnitude of the EFS-mediated responses that might indicate a postnatal maturation in colonic enteric neurotransmission.

\section{MATERIALS AND METHODS}

Animal model. Studies were performed using colonic smooth muscle obtained from neonatal (3- to 5-d-old), juvenile (2-wkold), and adult New Zealand White rabbits. In the adult, segments of proximal and distal colon were excised $5.0 \mathrm{~cm}$ distal to 
the cecum and $5 \mathrm{~cm}$ above the pelvic brim, respectively. These regions represent $20 \%$ (proximal) and $80 \%$ (distal) of the total length of the colon. Proximal and distal colonic segments from neonatal and juvenile animals were excised from areas corresponding to $20 \%$ and $80 \%$ of the total length of the colon.

Tissue preparation. The segments of proximal and distal colon were immediately opened along the mesenteric border, cleansed of fecal material, and pinned mucosal side up in a dissecting tray filled with room temperature $\left(23^{\circ} \mathrm{C}\right) \mathrm{KBS}$ of the following composition (in mM): $115 \mathrm{NaCl}, 4.6 \mathrm{KCl}, 2.1 \mathrm{MgCl}_{2}, 1.2 \mathrm{NaH}_{2} \mathrm{PO}_{4}$, $21.2 \mathrm{NaHCO}_{3}, 2.5 \mathrm{CaCl}_{2}$, and 11.5 glucose, maintained at $\mathrm{pH}$ 7.4 by continuously gassing the $\mathrm{KBS}$ with a $95 \% \mathrm{O}_{2}-5 \% \mathrm{CO}_{2}$ gas mixture.

With the aid of a stereomicroscope, full-thickness muscle strips were prepared by careful separation of the muscle from the mucosa and submucosa. The muscle strips were cut parallel to the circular muscle layer and measured approximately $2 \times 7$ $\mathrm{mm}$ for each age group.

Each muscle strip was placed in individual $10-\mathrm{mL}$ isolated tissue baths filled with warmed $\left(37^{\circ} \mathrm{C}\right)$, aerated KBS. One end of each strip was connected via an inelastic wire to an isometric force transducer (Harvard Biosciences, South Natick, MA), and the other end was attached to a glass rod that could be raised or lowered by adjustment of a fine micrometer. After a 1-h equilibration period, the muscle strips were stretched in $0.5-\mathrm{mm}$ increments until the length at which the maximal active contractile response to $\mathrm{ACh}(100 \mu \mathrm{M})$ was achieved. The response to EFS was determined with each muscle strip set at its respective maximal length. A permanent record of the contractile responses to ACh and EFS was obtained with a multichannel strip chart recorder (Kipp \& Zonen, Bohemia, NY).

EFS experiments. EFS was performed by using platinum wire electrodes placed parallel to the muscle strip. The electrodes were placed approximately $2 \mathrm{~mm}$ from the muscle strip. Square wave pulses were delivered to the tissues by using varying stimulus parameters. A supramaximal voltage of $80 \mathrm{~V}$ was used in all experiments. In a series of preliminary experiments, the responses of tissues from juvenile and adult animals to pulse widths of $0.5 \mathrm{~ms}$ and $0.9 \mathrm{~ms}$ were similar. This study reports the data obtained at a pulse width duration of $0.5 \mathrm{~ms}$. Stimulus frequency varied between 1.0 and $64 \mathrm{~Hz}$ and was applied to the tissue in a random pattern. The duration of the train of electrical impulses was $10 \mathrm{~s}$. At the end of each stimulus event, the tissues were rinsed with $\mathrm{KBS}$ and at least $15 \mathrm{~min}$ were allowed between stimulations. The neurogenic basis of the EFS-mediated responses was confirmed at the end of each experiment by stimulating the tissues in the presence of $1 \mu \mathrm{M}$ TTX. TTX was added $15 \mathrm{~min}$ before EFS.

In a series of preliminary experiments, the identity of the neurotransmitters involved in the contraction/relaxation responses to EFS was investigated pharmacologically using the following drugs: atropine sulfate $(100 \mu \mathrm{M})$, a muscarinic cholinergic antagonist; phentolamine mesylate $(100 \mu \mathrm{M})$, an $\alpha$-adrenergic antagonist; propranolol hydrochloride $(100 \mu \mathrm{M})$, a $\beta$ adrenergic antagonist; $4 \mathrm{Cl}$-Phe-VIP $(50 \mathrm{nM})$, a putative VIP receptor antagonist; and $\mathrm{N}^{\mathrm{G}}$-nitro-L-arginine methyl ester (100 $\mu \mathrm{M}$ ), an analog of $\mathrm{L}$-arginine that blocks the synthesis of nitric oxide from L-arginine. Each pharmacologic antagonist was added to the tissue bath $15 \mathrm{~min}$ before EFS. Muscle strips were challenged with only one antagonist.

Data analysis. Upon completion of an experiment, the length and weight of each muscle strip was determined and used to calculate the cross-sectional area of the muscle strip preparation as described previously (9). All contractions were normalized for differences in cross-sectional area and the data reported as stress in newtons per square meter $\left(\mathrm{N} / \mathrm{m}^{2} \times 10^{3}\right)$. The magnitudes of the contractile responses of tissues from neonates, juvenile animals, and adult animals were analyzed statistically using the $t$ test for unpaired data. All data are presented as mean \pm SEM.

\section{RESULTS}

Circular smooth muscle strips from the proximal and distal colon of neonates, juvenile rabbits, and adult rabbits demonstrated length-dependent increases in force. Within each age group, the active stress developed in response to $\mathrm{ACh}$ stimulation was similar for the proximal and distal colon. For both the proximal and distal colon, the active stress developed by tissues from neonates (proximal colon, $26 \pm 11 \mathrm{~N} / \mathrm{m}^{2} \times 10^{3}$; distal colon, $\left.25 \pm 12 \mathrm{~N} / \mathrm{m}^{2} \times 10^{3}\right)$ was significantly less $(p<0.05$; Fig. 1) than the active stress developed by tissues from juvenile animals (proximal colon, $53 \pm 10 \mathrm{~N} / \mathrm{m}^{2} \times 10^{3}$; distal colon, 55 $\pm 13 \mathrm{~N} / \mathrm{m}^{2} \times 10^{3}$ ). In turn, tissues from juvenile animals developed significantly less active stress $(p<0.01$; Fig. 1) than tissues from adult animals (proximal colon, $23 \pm 30 \mathrm{~N} / \mathrm{m}^{2} \times 10^{3}$; distal colon, $205 \pm 13 \mathrm{~N} / \mathrm{m}^{2} \times 10^{3}$ ).

EFS of circular smooth muscle from the proximal colon was characterized by the development of an on-contraction (Fig. 2). No on-relaxation or off-contraction was evident. For each age group, the magnitude of the on-contraction was frequency dependent (Fig. 3). Maximal responses developed at a stimulus frequency of $64 \mathrm{~Hz}$; the one-half-maximal responses occurred at stimulus frequencies between 2 and $4 \mathrm{~Hz}$. The magnitude of the maximum on-contraction increased with increasing postnatal age (Table 1). Atropine $100 \mu \mathrm{M}$ completely abolished EFSinduced on-contractions in all tissues examined. Administration of $1 \mu \mathrm{M}$ TTX also abolished EFS-induced on-contractions.

EFS of circular smooth muscle from the distal colon produced a prompt on-relaxation that was followed by an off-contraction (Fig. 2). Occasionally, at stimulus frequencies of 32 and $64 \mathrm{~Hz}$, the on-relaxation was replaced by an on-contraction (not shown in Fig. 2). Perhaps owing to the minimal resting tension of the distal colon, no consistent frequency-response relationship was noted for the on-relaxation. In contrast, the magnitude of the off-contraction in the distal colon was dependent on the stimulus frequency (Fig. 4). The maximum off-contraction occurred at 32 $\mathrm{Hz}$ and was significantly greater in tissues from adult rabbits compared with the response of tissues from neonates and juvenile animals $(p<0.05$; Table 1$)$. The magnitude of the on-contraction in the distal colon, when present, was significantly less than that of the on-contraction in the proximal colon or the offcontraction in the distal colon. Although atropine completely abolished the on-contraction when present in the distal colon, it had no effect on the off-contraction of the distal colon. TTX abolished both responses. TTX also abolished the on-relaxation. Although it was not the focus of this study to identify the mediators of the on-relaxation, our preliminary data obtained using $\mathrm{N}^{\mathrm{G}}$-nitro-L-arginine methyl ester and 4-Cl-Phe-VIP suggest that both VIP and nitric oxide may be involved, indicating the existence of a NANC inhibitory neurotransmission (Fig. 5).

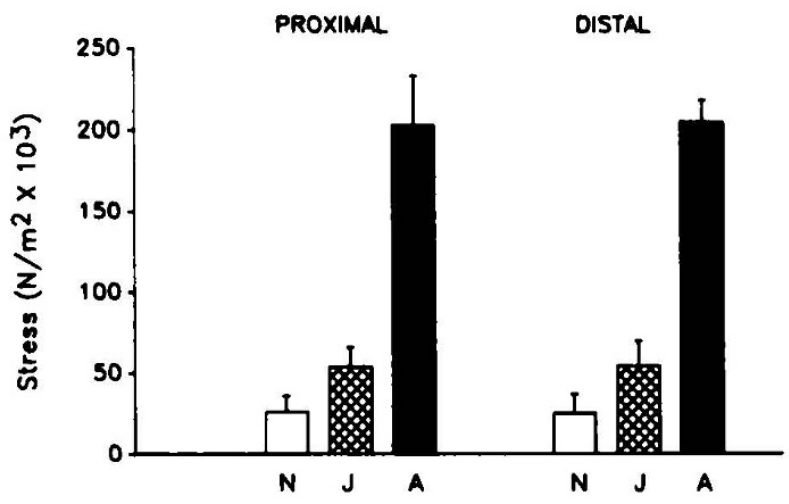

Fig. 1. Contractile response of circular smooth muscle from the proximal and distal colon of neonatal (3- to 5-d-old), juvenile (15-d-old), and adult rabbits to $\mathrm{ACh}\left(10^{-4} \mathrm{M}\right)$ stimulation. Maximal stress increased significantly as animals matured from neonates $(N)$ to juveniles $(J)$ to adults $(A)$ 


\section{ADULT COLON}

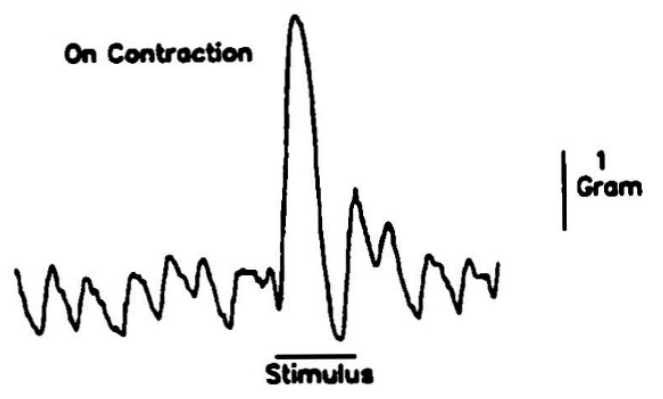

\section{Proximal Circular}

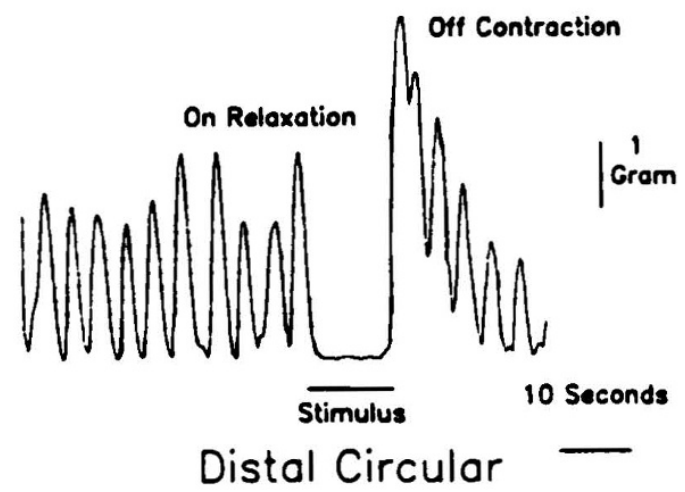

Fig. 2. Response of circular smooth muscle from the proximal (top) and distal (bottom) colon of adult rabbits to EFS. The proximal colon responds with contractions that occur only during EFS (on-contractions). The distal colon responds to EFS with a relaxation (on-relaxation) and a poststimulus contraction (off-contraction). On-contractions of the distal colon were only occasionally seen and only at high stimulus frequency. Qualitatively similar patterns of on- and off-contractions were observed in younger animals.

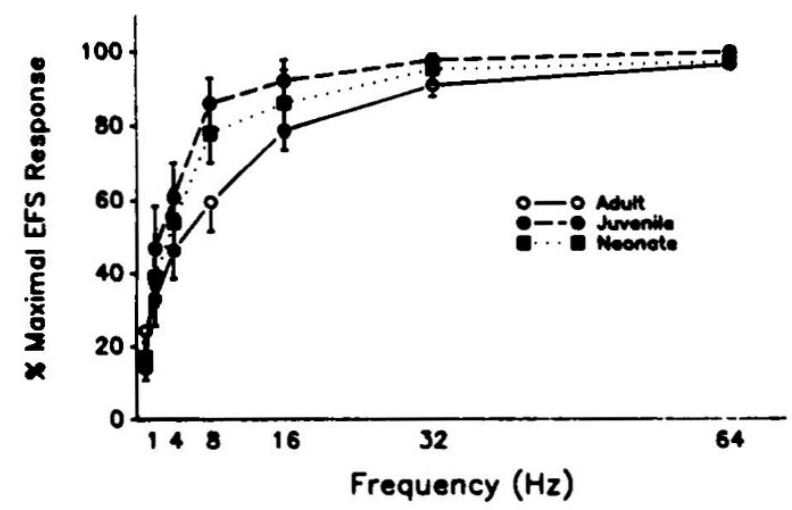

Fig. 3. Effect of increasing stimulus frequency on the on-contraction of colonic circular smooth muscle from the proximal colon of neonatal, juvenile, and adult rabbits. Data were normalized to the percentage of maximal on-contraction for each age group.
Table 1. Comparison of EFS-induced contractile responses of colonic smooth muscle from neonatal, juvenile, and adult rabbits*

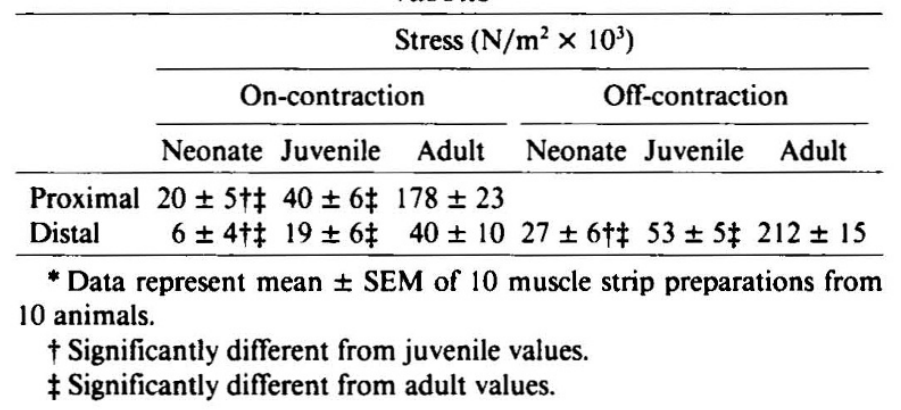

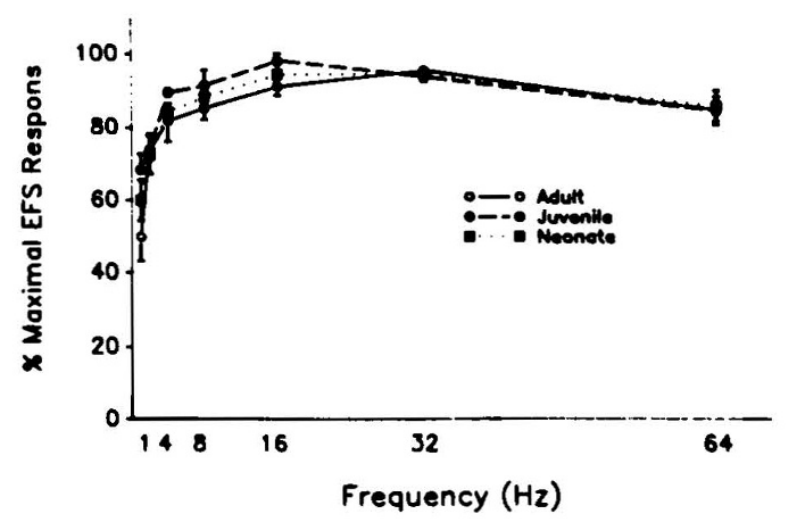

Fig. 4. Effect of increasing stimulus frequency on the off-contraction of colonic circular smooth muscle from the distal colon of neonatal, juvenile, and adult rabbits. Data were normalized to the percentage of maximal off-contraction for each age group.

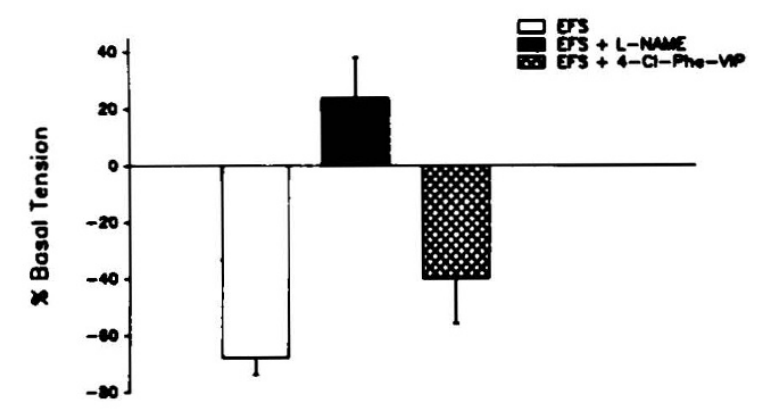

Fig. 5. Effect of $\mathrm{N}^{\mathrm{G}}$-nitro-L-arginine methyl ester $(L-N A M E)$ and 4Cl-Phe-VIP on EFS mediates on-relaxation of circular smooth muscle from the distal colon of adult rabbits. Data suggest that both nitric oxide and VIP are involved in the NANC inhibitory neurotransmission in this tissue.

\section{DISCUSSION}

In vivo studies indicate that the patterns of gastrointestinal motor activity, as well as transit times, differ in preterm and newborn infants compared with adults $(3,5-7)$. Although the factors responsible for the maturation of contractile activity remain unsettled, recent data suggest that a postnatal development in smooth muscle contractility may be involved. Using a variety of in vitro experimental designs, numerous investigators have shown that the increased force development that occurs over time can be demonstrated regardless of how the agonist activates the excitation-contraction coupling process, whether by receptor activation, membrane depolarization, or direct activation of the contractile proteins $(8-12)$. This has led to the hypothesis that the postnatal development of gastrointestinal motility involves maturation of the myogenic properties of smooth muscle. 
In the present study, the stress developed by circular smooth muscle from the proximal and distal colon in response to cholinergic stimulation increased as the animals developed from neonates to juveniles to adults. This result is consistent with our earlier observations $(20,21)$ and supports the findings of others $(17-19)$ that colonic smooth muscle is characterized by an increase in active force development during the postnatal period.

The regulation of colonic motility is determined by a complex interaction of neural and humoral factors with the myogenic properties of the smooth muscle. Recent data suggest that the proximal and distal colon have different physiologic functions at least in part as the result of differences in motility patterns (23, 25-27). In the proximal colon, motility patterns consistent with storage and mixing promote water and electrolyte absorption, whereas storage and evacuation of excretory products are the principal results of distal colon motor patterns. Christensen $e t$ al. (28) have reported that the myoelectric pattern of the proximal colon differs from the pattern recorded from the distal colon and is consistent with the different motility patterns, i.e. mixing and evacuation. Recently Snape et al. (23) reported that colonic smooth muscle from the proximal and distal colon of the adult rabbit evidences different contractile patterns in response to EFS. They proposed that regional differences in enteric neural control may underlie the different motility patterns and serve as an explanation for the different functions of the proximal and distal colon.

In the present study, EFS of circular smooth muscle from the proximal colon of adult rabbits exhibited atropine-sensitive oncontractions. In the distal colon, EFS of the circular smooth muscle was characterized by NANC-mediated on-relaxations and atropine-insensitive off-contractions. These results are consistent with the earlier report by Snape et al. (23) and suggest that fundamental differences may exist between the proximal and distal colon with respect to the involvement of the enteric nervous system in the regulation of colonic contractile activity.

Circular smooth muscle from the proximal and distal colon of neonatal and juvenile rabbits exhibited responses to EFS that were qualitatively similar to the results obtained from the adult. Atropine-sensitive on-contractions were characteristic of the proximal colon, whereas the distal colon evidenced NANCmediated on-relaxations and atropine-insensitive off-contractions. From these results, it would seem that the basic neuronal circuitry that modulates colonic contractile activity is in place and is functional in the immediate newborn period and does not undergo any postnatal maturation.

In contrast, age-related differences were observed with respect to the magnitude of the EFS-mediated on- and off-contractions. For both the proximal and distal colon, contractility increased as the animal matured from a neonate to an adult. These results are consistent with the data obtained with agonist stimulation and further support the hypothesis that colonic smooth muscle contractility undergoes a period of postnatal maturation. However, one cannot rule out the possibility that the differences may be due to age-related alterations in the production or release of neurotransmitter, differences in the degradation or uptake of neurotransmitter, or diminished end-organ sensitivity to neurotransmitter stimulation.

In summary, EFS of colonic smooth muscle from the proximal and distal colon of neonatal and juvenile rabbits produced patterns of contraction/relaxation consistent with those recorded from the adult. The results suggest that the pattern of enteric neurotransmission is established at the time of birth. Differences in the magnitude of the on- and off-contractions may reflect differences in the contractile abilities of smooth muscle from juvenile and adult animals.

\section{REFERENCES}

1. Cohen S 1981 Developmental characteristics of lower esophageal sphincter function: a possible mechanism for infantile achalasia. Gastroenterology 67:252-258

2. Hillemeier AC, Grill B, McCallum R, Gryboski J 1983 Esophageal and gastric abnormalities in gastroesophageal reflux during infancy. Gastroenterology 84:741-746

3. Tomomasa $T$, Itoh Z, Koizumi T, Kuroume $T 1985$ Nonmigrating rhythmic activity in the stomach and duodenum of neonates. Biol Neonate 48:1-9

4. Malloy MH, Morriss FH, Denson SE, Weisbrodt NW, Lichtenberger LM, Adcock III EW 1979 Neonatal gastric motility in dogs: maturation and response to pentagastrin. Am J Physiol 236:E562-E566

5. Gupta M, Brans YW 1978 Gastric retention in neonates. Pediatrics 62:26-29

6. Amarnath RP, Berseth CL, Malagelada JR, Perrault J, Abell TL, Hoffman AD 1989 Postnatal maturation of small intestinal motility in preterm and term infants. J Gastrointestinal Motility 1:138-143

7. Berseth CL 1989 Gestational evolution of small intestinal motility in preterm and term infants. J Pediatr 115:646-651

8. Denehy CM, Ryan JP 1986 Development of gallbladder contractility in the guinea pis. Pediatr Res 20:214-217

9. Zitterman J, Ryan JP 1990 Development of gastric antral smooth muscle contractility in newborn rabbits. Am J Physiol 21:G571-G575

10. Hillemeier AC, Bitar KN, Biancani P 1991 Developmental characteristics of the kitten antrum. Gastroenterology 101:339-343

11. Hyman PE, Martin MG, Tomomasa T, Jing J, Snape WJ 1989 Development of calcium channels in gastric smooth muscle. Pediatr Res 25:600-604

12. Tomomasa T, Yagi H, Kimura S, Snape WJ, Hyman PE 1989 Developmental changes in agonist mediated gastric smooth muscle contraction in the rabbit. Pediatr Res 26:459-461

13. Lambert $R$, Ryan JP 1990 Response to calcium of skinned gallbladder smooth muscle from newborn and adult guinea pigs. Pediatr Res 28:336-338

14. Lucas A, Bloom SR, Aynsley-Green A 1980 Development of gut hormone responses to feeding in neonates. Arch Dis Child 55:678-682

15. Berseth CL, Nordyke CK, Valdes MG, Furlow BL, Go VLW 1992 Responses of gastrointestinal peptides and motor activity to milk and water feedings in preterm and term infants. Pediatr Res 31:587-590

16. Zitterman J, Ryan JP 1989 Response of gastric fundus smooth muscle to electrical field stimulation. Gastroenterology 96:1116(abstr)

17. Heitkemper MM, Bond EF 1990 Age-related variations in jejunum and distal colon contractile response to thyrotropin-releasing hormone in vitro. Biol Neonate 58:8-15

18. Yagi H, Snape Jr WJ, Hyman PE 1991 Developmental changes in agonistmediated colonic smooth muscle contraction in the rabbit. Pediatr Res 29:20-23

19. Yagi H, Snaper Jr WJ, Hyman PE 1991 Perinatal changes in bombesinstimulated muscle contraction in rabbit smooth and colon. Gastroenterology 100:980-985

20. Martin JS, Ryan JP 1989 Length-tension characteristics and agonist responses of newborn rabbit colon. Physiologist 32:174(abstr)

21. Martin JS, Ryan JP 1990 Postnatal development of rabbit colonic smooth muscle contractility. Gastroenterology 99:1220(abstr)

22. Axelrod R, Martin J, Ryan JP 1992 Characterization of rabbit colonic smooth muscle contractile response to electrical field stimulation. Pediatr Res $21: 146$ (abstr)

23. Snape Jr WJ, Kim BH, Willenbucher R, Koelbel CB, Mayer Jr EA, Walsh JH 1989 Differences in the response of proximal and distal rabbit colonic muscle after electrical field stimulation. Gastroenterology 96:321-326

24. Costa M, Furness JB, Liewellyn-Smith IJ 1987 Histochemistry of the enteric nervous system. In: Johnson LR (ed) Physiology of the Gastrointestinal Tract. Raven Press, New York, pp $1-40$

25. Merlo A, Cohen $\mathrm{S} 1988$ Neuropeptide responses and mechanics of the proximal and distal feline colon in vitro. Am J Physiol 255:G787-G793

26. Tucker HJ, Snape Jr WJ, Cohen S 1979 Comparison of proximal and distal colonic muscle of the rabbit. Am J Physiol 237:E383-E388

27. Snape Jr WJ, Mayer EA, Koelbel CB, Hyman PE, Williams R, Root D 1989 Response of smooth muscle from proximal and distal human colon. J Gastrointestinal Motility 1:29-34

28. Christensen J, Caprilli R, Lund GF 1969 Electric slow waves in circular muscle of the cat colon. Am J Physiol 221:246-250 